\title{
A Dificuldade da Regularização dos Contribuintes Individuais ao Regime Geral da
}

\section{Previdência Social}

\section{The Difficulty of Regularization of Individual Taxpayers to the General Regime of Social Security}

\author{
Ana Carolina Nogueira Santos Cruz Cardoso ${ }^{1}$ \\ Paulo Henrique de Freitas Dutra Júnior ${ }^{2}$ e Thalyne Ribeiro Araújo ${ }^{3}$
}

\begin{abstract}
RESUMO: O Regime Geral da Previdência Social tem como função precípua assegurar todos os trabalhadores que estão fora dos regimes públicos. Todavia, objetiva-se demonstrar que nem todos os trabalhadores estão abarcados por tal instituto, como é o caso dos individuais, que prestam voluntariamente seus subsídios, sendo este equivalente a $20 \%$ do salário de contribuição. Através dos estudos de comparação estatísticos, feitos pela MELBOURNE, assim como as revisões bibliográficas, levantadas no presente trabalho, evidencia-se que a voluntariedade e a alta taxa de contribuição tornam-se empecilhos para a regulamentação de tais indivíduos ao sistema previdenciário. Dessa forma, articulou-se a Lei n. 12.470/11 que declara a possibilidade da alíquota aos contribuintes individuais ser em $11 \%$ na exclusão da aposentadoria por tempo de contribuição. Apesar da tentativa de redução da percentagem, constatou-se que, inicialmente, o plano fora um sucesso, porém, mostrou ser insuficiente depois de determinado lapso temporal. Sendo assim, há uma necessidade de reforma normativa de tal lei e/ou reajustar todo o sistema previdenciário para que os segurados possam se sentir atraídos por tal segmento da Seguridade Social.
\end{abstract}

PALAVRAS-CHAVE: contribuinte individual; previdência social; regulamentação.

ABSTRACT: The General Regime of Social Security has as its primary function to ensure all workers who are outside public schemes. However, it aims to demonstrate that not all workers are covered by such an institute, as is the case of individuals, who voluntarily provide their subsidies, which is equivalent to $20 \%$ of the salary contribution. Through the statistical comparison studies carried out by MELBOURNE, as well as the bibliographical reviews presented in the present study, it is evident that the voluntariness and the high rate of contribution become obstacles for the regulation of such individuals to the social security system. In this way, Law n. 12,470 / 11, which declares the possibility of the rate to the individual taxpayers being $11 \%$ in the exclusion of the retirement by time of contribution. Despite the attempt to reduce the percentage, it was found that initially the plan was a success, but it proved to be insufficient after a certain time span. Therefore, there is a need for a normative reform of such a law and / or to readjust the entire social security system so that the insured may feel attracted to such segment of Social Security.

KEYWORDS: individual taxpayer; social security; regulation.

\footnotetext{
${ }^{1}$ Graduada em Direito pela Universidade Ceuma (2001). Atualmente, é professora universitária da Universidade Ceuma, além de docente na Pós-Graduação em Direito do Trabalho na Universidade Ceuma e coordenadora da Pós-Graduação de Direito do Trabalho da Universidade Ceuma. Exerce a advocacia desde 2002 nas áreas de concentração em Direito Previdenciário e Direito do Trabalho. Tem experiência na área de Direito, com ênfase em Direito do Trabalho e Direito Previdenciário. E-mail: cruzcardoso@gmail.com

${ }^{2}$ Acadêmico do curso de Direito ( $5^{\circ}$ período) na Universidade Ceuma e estudante - pesquisador do Núcleo de Estudos em Justiça, Poder e Ética na Contemporaneidade (Nejupec) da Universidade Ceuma. E-mail: paulojunior.dutra@gmail.com

${ }^{3}$ Acadêmica do curso de Direito ( $5^{\circ}$ período) na Universidade Ceuma e estudante - pesquisadora do Núcleo de Estudos em Justiça, Poder e Ética na Contemporaneidade (Nejupec) e do Núcleo de Estudos em Urbanismo e Assessoria Jurídica Popular (Neajup) da Universidade Ceuma. E-mail: ribeirosthaly @ hotmail.com
} 


\section{Introdução}

O sistema previdenciário brasileiro possui, como uma das suas maiores dificuldades, a arrecadação monetária dos trabalhadores em ativa, já que certos parâmetros desse sistema se encontram nada atraentes aos olhos de seus segurados, como é o caso dos contribuintes individuais, que possuem elevada alíquota, equivalente a $20 \%$ de seu salário.

Tal conjuntura declama que os servidores, pertencentes ao Regime Geral da Previdência Social, e que se encontram nessa situação, acabam por não cumprir com suas obrigações arrecadatórias; sendo assim, permite a situação de irregularidade desses sujeitos à Previdência Social, além de dificultar a sua segurança quando tornarem-se inativos no mercado de trabalho. Afinal, de acordo com o princípio da solidariedade, os trabalhadores contribuem para que os inativos possam usufruir dos benefícios previdenciários, já que, quando estavam em ativa no mercado de trabalho, também contribuíam para a Previdência Social.

O legislador, ao visar a essa problemática, elaborou políticas públicas para que os contribuintes, dessa categoria autônoma, possam desfrutar dos serviços previdenciários. A Lei n¹2.470/2011 é um exemplo disso; nela, o trabalhador opta por contribuir com $20 \%$ do salário de contribuição, com todos os benefícios; ou com os $11 \%$ do salário de contribuição, porém sem a aposentadoria por tempo de contribuição, esta última é chamada de plano simplificado. Em suma, o plano simplificado demonstra uma possível solução para a regularização desses servidores, que se encontram na informalidade, assim como o papel do Estado na proteção aos seus cidadãos, os quais ainda permanecem em situação de irregularidade, não lhes sendo assegurados uma série de benefícios previdenciários.

\section{A Previdência e a Seguridade social}

A Seguridade Social, na Constituição Federal de 1988, fora definida como "um conjunto integrado de ações de iniciativa dos Poderes Públicos e da sociedade, destinadas a assegurar os direitos relativos à saúde, à previdência e à assistência social” (CRFB/88, art. 194, caput). Ou seja, a Seguridade é uma rede protetiva, organizada pelo Poder Constituinte, para que o Estado possa ofertar uma forma de proteção à sociedade.

A Constituição Brasileira de 1934 utilizou o termo Previdência ${ }^{4}$, porém sem o adjetivo social, sendo colocados juntos a partir da Constituição de 1946. A Previdência tem por função

\footnotetext{
4 "Previdência vem do latim pre videre, ver com antecipação as contingências sociais e procurar compô-las, ou o termo praevidentia, prever, antever.” (PINTO, Sergio Martins; Direito da Seguridade Social; 2011, p.285)
} 
auxiliar na subsistência daqueles que um dia vieram a produzir em sociedade, assim como aqueles que dependem desses trabalhadores. Para a manutenção e a garantia de funcionamento da Previdência Social, o Estado estipulou formas de regimes previdenciários, dentre eles o Regime Geral da Previdência Social.

O Regime Geral da Previdência Social atende todos os indivíduos que possam contribuir para a Previdência, exceto os servidores públicos, já que estes possuem seu próprio sistema previdenciário.

A forma de elaboração da Previdência Social é de competência do Estado, sendo regulada pelo Instituto Nacional de Seguro Social (INSS), tendo a sua arrecadação, dada pela contribuição dos seus segurados, fiscalizada e normatizada pela Receita Federal, sendo de Repartição Simples ${ }^{5}$ e de Benefício definido ${ }^{6}$.

Em suma, de acordo com Fabio Zambitte Ibrahim (2015, p. 172), "O RGPS é o regime de previdência social, sendo de aplicação compulsória a todos aqueles que exerçam algum tipo de atividade remunerada, exceto se esta atividade já gera filiação a determinado regime próprio de previdência."7 Ou seja, todos, que exercerem alguma atividade, se encontram obrigados a se filiar ao RGPS, excluindo-se dessa obrigação os que estão no RPPS.

\section{Os Segurados da Previdência Social}

A Previdência Social, como um todo, adota o modelo "pay as you go system" em que os ativos contribuem para os benefícios dos inativos, ao demostrar o princípio da Solidariedade. De acordo com o autor Ivan Kerztman:

A solidariedade do sistema previdenciário, em síntese, é o princípio que acarreta a contribuição dos segurados para o sistema, com a finalidade de mantê-lo, sem que necessariamente usufrua dos seus benefícios. Uma vez nos cofres da previdência social, os recursos serão destinados a quem realmente deles necessitar. (Kerztman, 2015, p. 33)

Participam desse grupo, como segurados, aqueles que exercem ou exerceram atividade de cunho oneroso, aqueles que não desempenham atividades (desempregados) ou que não têm remuneração pelos seus afazeres (dona de casa). Tais sujeitos podem adentrar nessa proteção social,

\footnotetext{
${ }^{5}$ Ivan Kertzman (2015, p.34) define "No regime de repartição simples, as contribuições são depositadas em um fundo único. Os recursos são, então, distribuídos a quem deles necessitar.” (KERTZMAN, Ivan. Curso Prático de Direito Previdenciário. 12a ed. Bahia: JusPodivm. 2015).

${ }^{6}$ Ivan Kertzman (2015, p. 34) define "No regime de benefício definido, as regras para o cálculo do valor dos benefícios são previamente estabelecidas. É o que ocorre com a previdência pública brasileira, que tem suas regras definidas por força de lei.”. (KERTZMAN, Ivan. Curso Prático de Direito Previdenciário. 12. ed. Bahia: JusPodivm. 2015).

${ }^{7}$ IBRAHIM, Fábio Zambitte. Curso de Direito Previdenciário. 21 a ed. Rio de Janeiro: Impetus. 2015.
} 
através do cadastro do RGPS, mediante comprovação dos dados pessoais e de outros elementos necessários e úteis à sua caracterização. Por exemplo, o autônomo deve apresentar um documento que caracterize o exercício da atividade profissional. A filiação decorre imediatamente com o exercício da atividade remunerada para os obrigatórios, e aos facultativos com o pagamento da primeira contribuição.

No que concerne aos segurados da previdência, dá-se importância acentuada aos autônomos, que possuem, em suas características principais, quase os mesmos requisitos de uma relação de emprego; assim o autor Mauricio Godinho Delgado os conceitua: "toda pessoa natural que contrate, tácita ou expressamente, a prestação de seus serviços a um tomador, a este efetuados com pessoalidade, onerosidade, não eventualidade e subordinação" ${ }^{8}$. (Grifo nosso).

Ao possuir a noção desses elementos, tem-se que, exceto pela subordinação jurídica, os contribuintes individuais apresentam, no lugar desta, a autonomia. No que diz respeito ao conceito de autonomia e subordinação, usam-se as palavras de Mauricio Godinho Delgado (p.373, 2017) e de Vólia Bonfim (p.266, 2015), respectivamente, "a autonomia traduz a noção de que o próprio prestador é que estabelece e concretiza, cotidianamente, a forma de realização dos serviços que pactuou prestar," 9 e "o dever de obediência ou o estado de dependência na conduta profissional, a sujeição às regras, orientações e normas estabelecidas pelo empregador inerentes ao contrato, à função, desde que legais e não abusivas." ${ }^{10}$ Ou seja, autônomo é todo aquele que constitui a sua forma de trabalho, sem que terceiros intervenham em sua forma de prestar serviços, sendo comprovada a sua insubordinação, na execução da atividade compactuada, observando-se a intensidade dos mandamentos feitos pelo contratante.

Existe ainda a possibilidade de ocorrer a exclusão de outro elemento da relação de emprego, a pessoalidade, que consiste na "ideia de intransferibilidade, ou seja, de que somente uma específica pessoa física, e nenhuma outra em seu lugar, pode prestar o serviço ajustado" (Martinez, Luciano, p. $254-255,2016)^{11}$. Visto que o trabalhador, em qualquer momento, poderá faltar a pessoalidade com seu tomador, e ser até mesmo trocado por uma pessoa jurídica durante a prestação de serviço.

Apesar da importância dada, na presente pesquisa, ao autônomo, este segurado não se encontra como o principal contribuinte da previdência social, ficando o maior quantitativo aos segurados empregados, já que, em suas relações de custeio, é o empregador quem recolhe as

\footnotetext{
${ }^{8}$ DELGADO, Maurício Godinho. Curso de direito do trabalho. 12. ed. São Paulo: LTR. 2017.

${ }^{9}$ DELGADO, Maurício Godinho. Curso de direito do trabalho. 12a ed. São Paulo: LTR. 2017.

${ }^{10}$ CASSAR, Vólia Bonfim, Direito do Trabalho. $11^{a}$ ed. São Paulo: Método. 2015

11 MARTINEZ, Luciano; Curso de Direito do Trabalho. $7^{\mathrm{a}}$ ed. São Paulo: Saraiva. 2016
} 
contribuições para a Previdência dos seus subordinados, como afirma João Batista Lazzari e Carlos Alberto Pereira de Castro (p.118, 2016):

\begin{abstract}
A lei estabelece ao empregador que este venha a recolher a contribuição a que está obrigado e, ainda, retenha a contribuição dos empregados a seu serviço, recolhendo-as também aos cofres do Fundo do Regime Geral de Previdência Social, tal responsabilidade é intransferível e, caso descumprida, arcará ele - o empregador - unicamente com os efeitos decorrentes do descumprimento da norma, não se penalizando os empregados com a infração legal. ${ }^{12}$
\end{abstract}

É devido a essa sistemática que os trabalhadores da relação de emprego hão de ter a sua contribuição concretizada, já que independe deles o pagamento. Diferentemente, ocorre aos contribuintes individuais, devido à ausência de um empregador que preste conta a tal sistema, pois cabe, assim, ao legislador a incumbência de criar uma regulamentação para que se possa englobar tais sujeitos à Previdência Social.

\title{
A regulamentação do salário de contribuição e o plano legislativo voltado ao incentivo dos contribuintes individuais no âmbito previdenciário.
}

No ordenamento jurídico, os contribuintes individuais foram instituídos pela Lei $\mathrm{n}$. 8.212/91, enquadrando-os como segurados obrigatórios da Previdência Social, sendo estes, os autônomos, empresários e equiparados ao trabalhador autônomo. Ademais, tem-se a definição estabelecida pelo próprio Anuário Estatístico da Previdência Social que dispõe:

Contribuinte individual - aquele que presta serviços de natureza urbana ou rural, em caráter eventual, a uma ou mais empresas, sem relação de emprego; ou, aquele que exerce, por conta própria, atividade econômica remunerada de natureza urbana ou rural, com fins lucrativos ou não. (Anuário Estatístico da Previdência Social. p.616, 2015.)

Para a participação nos Regimes Previdenciários, os contribuintes individuais deverão realizar uma forma de prestação pecuniária, que, antigamente, para a categoria dos individuais, era o salário-base, atualmente denominado salário de contribuição, regulado no art. 28, inciso III, e seus $\S \S 3^{\circ}$ e $5^{\circ}$ da Lei n. $8.212 / 91 .^{13}$

\footnotetext{
${ }^{12}$ CARLOS, Alberto Pereira; LAZZARI, João Batista. Manual de Direito Previdenciário. 19 $9^{\text {a }}$ ed. Rio de Janeiro: Forense LTDA. 2016.

${ }^{13}$ Art. 28. Entende-se por salário-de-contribuição:

III - para o contribuinte individual: a remuneração auferida em uma ou mais empresas ou pelo exercício de sua atividade por conta própria, durante o mês, observado o limite máximo a que se refere o $\S 5^{\circ}$;

$\S 3^{\circ} \mathrm{O}$ limite mínimo do salário-de-contribuição corresponde ao piso salarial, legal ou normativo, da categoria ou, inexistindo este, ao salário mínimo, tomado no seu valor mensal, diário ou horário, conforme o ajustado e o tempo de trabalho efetivo durante o mês.
} 
A legislação previdenciária dita a forma do recolhimento das arrecadações ${ }^{14}$, ao alegar que a iniciativa é própria do trabalhador e essa mesma regulamentação, estabelecida no art.21, caput ${ }^{15}$, define a alíquota desses contribuintes no valor de $20 \%$ em cima do salário de contribuição.

Ao visar a toda essa sistemática, promovida pela regulamentação previdenciária, tem-se a seguinte problemática: a elevada taxa de alíquota aos contribuintes individuais; coube ao legislador então a criação de uma norma que tornasse mais atrativa e menos onerosa a forma de pagamento à Previdência Social.

A Lei $n^{\circ} 12.470 / 11$ estabeleceu uma alíquota diferenciada aos microempreendedores individuais, aos facultativos e aos contribuintes individuais, ao realizar uma alteração na Lei n. 8.212/91, ênfase no art. 21 e seu $\S 2^{\circ}$, inciso I; tal Lei reduziu a alíquota, que a primeira estabeleceu, de $20 \%$ para $11 \%$ em cima do salário de contribuição. Entretanto, ao realizar essa redução, o segurado necessitará abdicar da aposentadoria por tempo de contribuição, sem perder os demais benefícios, como: a aposentadoria por idade, o auxílio-doença, o salário-maternidade, a pensão por morte, o auxílio-reclusão e a aposentadoria por invalidez.

Caso o trabalhador escolha pelo plano simplificado dos $11 \%$ e, futuramente, queira aderir a aposentadoria por tempo de contribuição, poderá, com base no $\S 3^{\circ}$ do art. 21 , complementar o subsídio mensal sobre o valor do limite mínimo do salário de contribuição em vigor, constatando-se que a diferenciação deve ser complementada, já que o percentual, antigamente, era 20\% mais o acréscimo de juros moratórios.

\section{Os Anuários Estatísticos da Previdência Social}

A tentativa de melhoria da arrecadação dos contribuintes individuais, com a criação da Lei n. 12.470/2011, demonstra, através dos Anuários da Previdência Social dos anos de 2012 e 2015, uma melhoria temporária; todavia, uma possível falha, no decorrer do tempo, pode ocorrer, como aponta a seguinte tabela (dados dos anos de 2011 a 2015). Inicialmente, 2.022.517 (dois milhões, vinte e dois mil e quinhentos e dezessete) contribuintes adentraram no plano simplificado, e, de acordo com a última pesquisa disponível, que foi realizada em 2015, esse número subiu para

$\S 5^{\circ} \mathrm{O}$ limite máximo do salário-de-contribuição é de $\mathrm{Cr} \$ 170.000,00$ (cento e setenta mil cruzeiros), reajustado a partir da data da entrada em vigor desta Lei, na mesma época e com os mesmos índices que os do reajustamento dos benefícios de prestação continuada da Previdência Social.

${ }^{14}$ Art. 30. A arrecadação e o recolhimento das contribuições ou de outras importâncias devidas à Seguridade Social obedecem às seguintes normas:

II - Os segurados, contribuinte individual e facultativo, estão obrigados a recolher sua contribuição por iniciativa própria, até o dia quinze do mês seguinte ao da competência.

${ }^{15}$ Art. 21. A alíquota de contribuição dos segurados, contribuinte individual e facultativo, será de vinte por cento sobre o respectivo salário-de-contribuição. 
2.446.602 (dois milhões, quatrocentos e quarenta seis mil e seiscentos e dois) segurados autônomos. Ou seja, houve um aumento, de 2011 até o ano de 2015, de 424.085 (quatrocentos e vinte e quatro mil e oitenta e cinco) trabalhadores individuais optantes por esse plano simplificado, o que resultaria em um sucesso de tal medida legislativa.

\begin{tabular}{|ccc|}
\hline TIPO DE CONTRIBUINTE & ANO & QUANTIDADE DE CONTRIBUINTES \\
\hline & 2011 & 2.022 .517 \\
\cline { 2 - 3 } CONTRIBUINTE & 2012 & 2.108 .848 \\
\cline { 2 - 3 } INDIVIDUAL & 2013 & 2.284 .633 \\
\cline { 2 - 3 } PLANO SIMPLIFICADO & 2014 & 2.468 .935 \\
\cline { 2 - 3 } & 2015 & 2.446 .602 \\
\hline
\end{tabular}

Tabela 1: Contribuintes individuais no Plano Simplificado

Entretanto, no último anuário, disponível pela Previdência Social no ano de 2015, ocorreu uma recaída, de 2014 para o referido ano da pesquisa; ou seja, em 2014, apresentava-se o equivalente a 2.468 .935 (dois milhões, quatrocentos e sessenta e oito mil, e novecentos e trinta cinco) trabalhadores autônomos na seara previdenciária, esses dados, se comparados aos de 2015, demonstram um retrocesso, tendo-se uma perda de 22.327 (vinte e dois mil, trezentos e vinte sete) contribuintes individuais que optaram pelo plano simplificado.

\section{O olhar internacional voltado para a Previdência Social Brasileira}

De acordo com as pesquisas feitas pela instituição internacional, MELBOURNE MERCER GLOBAL PENSION INDEX ${ }^{16}$, que realiza um estudo comparativo entre as previdências do mundo todo, o Brasil encontra-se na $16^{\mathrm{a}}$ (décima sexta) posição do ranking mundial, com 55 (cinquenta e cinco) pontos de 100 (cem); os três primeiros lugares são: da Dinamarca, com 80 (oitenta) pontos; dos Países Baixos, com 80 (oitenta); e da Austrália, com 77 (setenta e sete) pontos.

O Brasil possui a classificação $C$, pois consiste em "um sistema que tem algumas características boas, mas também tem grandes riscos e/ou deficiências que devem ser abordadas. Sem essas melhorias, sua eficácia e/ou sustentabilidade a longo prazo pode ser questionada. " 17

Em suma, o Brasil possui uma crise, no que concerne à contribuição dos segurados aos regimes previdenciários, e necessita aplicar certas medidas de melhorias, como o abandono do sistema de repartição simples ao capitalizado.

16 MELbOURne MERCER GLObAl PENSION INDEX. Austrália, 2016. Disponível em: < https://www.globalpensionindex.com/country-summaries-2/brazil/ >. Acesso: 19 ago. 2017.

17 (MELBOURNE MERCER GLOBAL PENSION INDEX. Austrália, 2016. Disponível em:<http://gamaca.com.br/wpcontent/uploads/2016/11/RRF19921_MMGPI_4Page_Infographic_0916A-PT-WEB.pdf >. Acesso: 19 ago. 2017.) 


\section{Considerações finais}

Ao analisar-se tais dados, pondera-se que, possivelmente, haverá uma queda dos contribuintes individuais optantes por essa medida legislativa; os desafios, que o sistema previdenciário enfrenta, podem ser uma das causas dessas diminuições. A MELBOURNE MERCER GLOBAL PENSION INDEX aponta esses dados e relata que o Brasil possui certas características boas, mas, futuramente, poderá vir a falhar caso não determine mudanças na sua forma de organização.

Dessa forma, constata-se que uma espécie de solução possível seria a troca da repartição simples pelo método capitalizado.

O modelo de repartição simples, apesar de adotar a solidariedade do sistema previdenciário, não corresponde aos interesses particulares dos seus segurados; tais interesses são a segurança dos segurados perante as eventualidades que os tornem incapacitados para o âmbito trabalhista.

O sistema de capitalização detém, como sua prioridade, a individualidade, em que cada segurado arcará com a sua própria Previdência. Esse sistema funciona como uma espécie de poupança com o agravante de que o sujeito não controlaria o dinheiro investido, devendo o Estado controlar o mínimo quantitativo para a arrecadação. Visa-se, desse modo, não deixar aos empregadores meios de determinar uma baixa da contribuição dos seus empregados, assim como não permitir aos demais trabalhadores, como os autônomos, contribuírem com uma quantidade insignificante a ponto de não conseguir a sua subsistência.

Em outras palavras, caso o sujeito invista em sua própria previdência, terá a sociedade, como um todo, maior propulsão econômica devido à acumulação das poupanças previdenciárias, não dependendo do sistema da Previdência Social utilizar-se de grandes retiradas do PIB para custear os benefícios desse sistema ("grandes retiradas" o que não significa que o Estado deixará de custear parte do sistema, logo não ficará só os contribuintes no direito de custear tal instituto), o que acarretaria em uma diminuição nos gastos do Estado, o qual poderá investir nas demais áreas que o meio social necessita, como, por exemplo, um dos segmentos da Seguridade Social, a Saúde.

Além do mais, existe ainda a possibilidade do sistema de Capitalização sofrer uma espécie de flexibilização, ao permitir que as partes majoritárias das contribuições sejam realizadas pelos trabalhadores beneficiários e o restante por aqueles que virão a compor os servidores dos regimes 
previdenciários, em conjunto com a União, retomando-se, assim, mesmo que parcialmente, a finalidade do princípio constitucional que determina o apoio entre as gerações, a Solidariedade.

\section{REFERÊNCIAS}

BALERA, Wagner. Noções preliminares de direito previdenciário. São Paulo: Quartier Latin, 2004.

BRASIL. Constituição da República Federativa do Brasil de 1988. Disponível em: http://www.planalto.gov.br/ccivil_03/constituicao/constituicao.htm. Acesso em 02 set. 2017.

BRASIL. Consolidação das Leis do Trabalho. Disponível em: http://www.planalto.gov.br/ccivil_03/decreto-lei/Del5452.htm. Acesso em 02 set. 2017.

BRASIL. Lei Orgânica da Previdência Social. Disponível em: http://www.planalto.gov.br/ccivil_03/leis/L8212cons.htm. Acesso em 02 set. 2017.

BRASIL. MINISTÉRIO DA FAZENDA. SECRETARIA DE PREVIDÊNCIA. INSTITUTO NACIONAL DO SEGURO SOCIAL. EMPRESA DE TECNOLOGIA E INFORMAÇÕES DA PREVIDÊNCIA. Anuário Estatístico da Previdência Social 2012. Vol. 21 Brasília - DF, 2012.

BRASIL. MINISTÉRIO DA FAZENDA. SECRETARIA DE PREVIDÊNCIA. INSTITUTO NACIONAL DO SEGURO SOCIAL. EMPRESA DE TECNOLOGIA E INFORMAÇÕES DA PREVIDÊNCIA. Anuário Estatístico da Previdência Social 2015. Vol. 24 Brasília - DF, 2015.

CARLOS, Alberto Pereira; LAZZARI, João Batista. Manual de Direito Previdenciário. $19^{a}$ ed. Rio de Janeiro: Forense LTDA. 2016.

CASSAR, Vólia Bonfim, Direito do Trabalho. $11^{\mathrm{a}}$ ed. São Paulo: Método. 2015

DELGADO, Maurício Godinho. Curso de direito do trabalho. 12. ed. São Paulo: LTR. 2017

IBRAHIM, Fábio Zambitte. Curso de Direito Previdenciário. $21^{\text {a }}$ ed. Rio de Janeiro: Impetus. 2015.

SERAU JÚNIOR, Marco Aurélio. Resolução do conflito previdenciário e direitos fundamentais. São Paulo: LTR Editora, 2015.

KERTZMAN, Ivan. Curso Prático de Direito Previdenciário. 12ª ed. Bahia: JusPodivm. 2015.

MARTINEZ, Luciano. Curso de Direito do Trabalho. 7ª ed. São Paulo: Saraiva. 2016.

MARTINS, Sérgio Pinto, Direito da Seguridade Social, 32a edição, São Paulo, editora Atlas s.a, 2012.

MELBOURNE MERCER GLOBAL PENSION INDEX. Austrália, 2016. Disponível em: < http://gamaca.com.br/wpcontent/uploads/2016/11/RRF19921_MMGPI_4Page_Infographic_0916APT-WEB.pdf >. Acesso: 19 ago. 2017.

MELBOURNE MERCER GLOBAL PENSION INDEX. Austrália, 2016. Disponível em: < https://www.globalpensionindex.com/country-summaries-2/brazil/ >. Acesso: 19 ago. 2017. 